\title{
Regulatory function of peroxiredoxin I on 4-(methylnitrosamino)-1-(3-pyridyl)-1-butanone-induced lung cancer development (Review)
}

\author{
HU-NAN SUN $^{1 *}$, CHEN-XI REN $^{1 *}$, YI-XI GONG $^{1 *}$, DAN-PING XIE $^{1}$ and TAEHO KWON ${ }^{2}$ \\ ${ }^{1}$ College of Life Science and Biotechnology, Heilongjiang Bayi Agricultural University, Daqing, \\ Heilongjiang 163319, P.R. China; ${ }^{2}$ Primate Resources Center, Korea Research Institute of Bioscience \\ and Biotechnology, Jeongeup, Jeonbuk 56216, Republic of Korea
}

Received January 28, 2021; Accepted March 17, 2021

DOI: $10.3892 / \mathrm{ol} .2021 .12726$

\begin{abstract}
Smoking is a major cause of lung cancer, and 4-(methylnitrosamino)-1-(3-pyridyl)-1-butanone (NNK) is one of the most important carcinogens in cigarette smoke. NNK modulates the expression of peroxiredoxin (Prdx) I in lung cancer. Prdx1 is upregulated in lung squamous cell carcinoma and lung adenocarcinoma, and considered a potential biomarker for lung cancer. The current article reviewed the role and regulatory mechanisms of Prdx1 in NNK-induced lung cancer cells. Prdx1 protects erythrocytes and DNA from NNK-induced oxidative damage, prevents malignant transformation of cells and promotes cytotoxicity of natural killer
\end{abstract}

Correspondence to: Dr Taeho Kwon, Primate Resources Center, Korea Research Institute of Bioscience and Biotechnology, 351-33 Neongme-gil, Ibam-myeon, Jeongeup, Jeonbuk 56216, Republic of Korea

E-mail: kwon@kribb.re.kr

Dr Hu-Nan Sun, College of Life Science and Biotechnology, Heilongjiang Bayi Agricultural University, 2 Xingyanglu, Daqing, Heilongjiang 163319, P.R. China

E-mail: sunhunan76@163.com

*Contributed equally

Abbreviations: NNK, 4-(methylnitrosamino)-1-(3-pyridyl)1-butanone; Prdx1, peroxiredoxin I; ROS, reactive oxygen species; Prdx, peroxiredoxins; NK cells, natural killer cells; NSCLC, non-small cell lung cancer; TGF- $\beta 1$, transforming growth factor- $\beta 1$; EMT, epithelial mesenchymal transition; Nrf2, nucleosome 2-related factor 2; SOD, superoxide dismutase; $\mathrm{H}_{2} \mathrm{O}_{2}$, hydrogen peroxide; AM, alveolar macrophages; IL-12, interleukin-12; TNF, tumor necrosis factor; IL-10, interleukin 10; COX-2, cyclooxygenase 2; PGE2, prostaglandin E2; nAChRs, nicotinic acetylcholine receptors; PI3K, phosphatidylinositol-3-kinase; AKT, protein kinase B; TxA2, thromboxane A2; PTEN, phosphatase and tensin homolog

Key words: EMT, lung cancer, NNK, oxidative damage, Peroxiredoxin I cells, hence suppressing tumor formation. In addition, Prdx1 has the ability to prevent NNK-induced lung tumor metabolic activity and generation of large amount of reactive oxygen species (ROS) and ROS-induced apoptosis, thus promoting tumor cell survival. In contrast to this, Prdx1, together with NNK, can promote the epithelial-mesenchymal transition and migration of lung tumor cells. The signaling pathways associated with NNK and Prdx1 in lung cancer cells have been discussed in present review; however, numerous potential pathways are yet to be studied. To develop novel methods for treating NNK-induced lung cancer, and improve the survival rate of patients with lung cancer, further research is needed to understand the complete mechanism associated with NNK.

\section{Contents \\ 1. Introduction \\ 2. NNK \\ 3. $\operatorname{Prdx} 1$ \\ 4. Conclusions}

\section{Introduction}

Environmental risk factors, such as cigarette smoking and asbestos, lead to increased risk of lung cancer. Before the 20 th century, incidences of lung cancer were very rare, up to 1898 , only 140 cases of lung cancer were reported in the world medical literature (1). Since the start of tobacco usage, the morbidity and mortality rates of lung cancer have been gradually rising (2,3), and according to WHO statistics, lung cancer has the highest incidence and mortality rate among the 36 most common cancers in the world in 2018 (3). Studies have shown that smoking is directly related to lung cancer (4). According to the statistical data from the World Health Organization, lung cancer was the leading cause of cancer-associated death in 2018; currently there are 300 million tobacco users worldwide, and there are 8 million deaths every year (3).

Multiple studies have shown that 4-(methylnitrosamino)-1 -(3-pyridyl)-1-butanone (NNK) is the most potent carcinogen 
in tobacco that causes lung cancer $(5,6)$. NNK can induce DNA strand breaks and DNA adduct formation, while its metabolism results in the generation of hydroxyl and other reactive oxygen radica9 1s, which in turn causes lung cancer (7). A study by Yeh et al (8) demonstrated that the incubation of A549 lung cancer cells with NNK results in increased levels of reactive oxygen species (ROS) formation (8). Furthermore, it has been shown that NNK induces oxidative stress by increasing ROS level in cells and promotes lung cancer progression, which may be associated with the changes in the expression of the genes related to ROS metabolism (9).

The antioxidant defense system in mammalian cells prevents excessive ROS accumulation (10) and maintains the intracellular redox balance. The peroxiredoxin $(\operatorname{Prdx})$ family of proteins function in the cellular oxidative defense system, which eliminates ROS (11) and affects various cellular activities, such as cell proliferation, differentiation (12), apoptosis (13) and gene expression (14). Prdx1 inhibits NNK-induced DNA damage and prevents the development of lung tumors (15-17). NNK-induced changes in the expression of peroxide redox proteins in lung cancer cells indicates that Prdx1 may be involved in the detoxification of ROS during NNK-induced oxidative stress (17). Hence, Prdx1 protects the cells, DNA and proteins from NNK-induced damage, and thus development of lung cancer. The interplay between NNK and Prdx1 has recently gained attention (12,16-18), and an improved understanding of the role of Prdx1 in the development of NNK-induced lung cancer may shed new light towards the development of therapeutic strategies against lung cancer.

\section{NNK}

$\mathrm{NNK}$, an aromatic compound, is the most potent carcinogen in tobacco smoke (19). In multiple organs, the nicotine in tobacco is rapidly metabolized by cytochrome (CY) P450. In the liver, it is hydroxylated by CYP2A26 at the 2'position to form an amino ketone intermediate, which is subsequently nitrosated to produce NNK (20).

In vivo experiments show that $\mathrm{NNK}$ is metabolized by three methods: Carbonyl reduction, pyridine oxidation and $\alpha$-hydroxylation (21). In the carbonyl reduction process, NNK is carbonylated by $11 \beta$-hydroxysteroid dehydrogenase to form 4-(methylnitrosamino)-1-(3-pyridyl)-1-butanol (NNAL), which is then metabolized by glucuronidation to produce NNAL-glucuronic acid (22). During oxidation of pyridine nitrogen, CYP450 2B1 and CYP3A4 metabolize NNK to NNK-N-oxide (23). The $\alpha$-hydroxylation process includes two modes: A-hydroxylation of the methyl carbon adjacent to the $\mathrm{N}$-nitroso nitrogen and $\alpha$-hydroxylation of the methylene carbon adjacent to the $\mathrm{N}$-nitroso nitrogen. NNK is hydroxylated at the methyl group adjacent to N-nitroso to form $\alpha$-hydroxymethyl-NNK, which then decomposes to form formaldehyde and 4-(3-pyridyl)-4-oxobutane-1diazohydroxide. Finally, the latter reacts with water to form ketone alcohol. The methylene carbon of NNK can also be hydroxylated to generate an unstable $\alpha$-methylene hydroxyl-NNK, which quickly decomposes to methane diazohydroxide and keto aldehyde, and finally keto aldehyde oxidizes to form keto acid (19) (Fig. 1).
Using Syrian golden hamster tissue sections, it has been shown that lung tissue has a lower NNK total metabolic rate compared with that of kidney and liver tissues (24). The oxidative metabolism of NNK to DNA-reactive intermediates by $\alpha$-hydroxylation accounts for $13-31 \%$, pyridine nitrogen oxidation accounts for $5-22 \%$, while carbonyl group reduction of NNK to NNAL accounts for $47-81 \%$ of the total metabolism of NNK in the lung. The total metabolism of NNAL in all the tissues is $\sim 10$ times lower compared with that of NNK (24). The difference in the metabolic rate of various NNK metabolites is one of the reasons that the lung is more susceptible to the NNK carcinogen (24).

\section{Prdx1}

Prdxs, a class of antioxidant protective proteins, play an important role in the elimination of ROS and cancer development (25). Prdx1 is a member of the Prdxs family of proteins, which is primarily localized in the cytosol, as well as found in the nucleus, plasma, membrane and centrosome (11). Prdx1 is considered to be an important antioxidant protein (15), and exerts an antioxidant effect by forming a homodimer. The $\mathrm{Cys}^{52}$ sulfhydryl group on one peptide chain and the Cys ${ }^{172}$ sulfhydryl group on the other peptide chain are dehydrogenated to form an intermolecular disulfide bond, $\mathrm{Cys}^{52} \mathrm{~S}_{-} \mathrm{SCys}^{172}$, which reduces peroxides by providing hydrogen ions, thereby detoxifying them (26). Prdx1 is highly sensitive to hydrogen peroxide $\left(\mathrm{H}_{2} \mathrm{O}_{2}\right)$, among various peroxides (11).

In most cancer cells, such as breast, esophageal and lung cancer, Prdx1 can removes excess intracellular ROS, maintains ROS balance and protects the cells from oxidative stress-induced DNA damage (27). Furthermore, by eliminating ROS, Prdx1 prevents oxidative stress-induced mutations in the P53 and $K$-Ras genes, thereby inhibiting tumor formation, suppressing lung cancer cell proliferation, invasion and migration, and increasing radiation sensitivity of the cancer cells $(15,28)$. Cys ${ }^{52}$ is the active center of Prdx1 (29), which either reacts with $\mathrm{H}_{2} \mathrm{O}_{2}$ (30) or combines with heme; hence, Prdx1 is also called as heme-binding protein 23 (31). $\operatorname{Prdx} 1$ acts as a scavenger for the cytoplasmic heme and has an important inhibitory effect on heme toxicity (32). Furthermore, Prdx1 enhances the immune activity of natural killer (NK) cells against tumor cells, and is also known as natural killer enhancement factor (11). It has been shown that Prdx1 can effectively prevent lung cancer progression by enhancing the tumor killing effects of NK cells $(33,34)$. Prdx1 is overexpressed in non-small cell lung cancer (NSCLC) cells, which has been demonstrated to promote transforming growth factor- $\beta 1$ (TGF- $\beta 1$ )-induced epithelial mesenchymal transition (EMT) and A549 cell migration (35). In addition, the interaction between Prdx1 and nuclear erythroid 2-related factor 2 (Nrf2) can significantly affect the proliferation of lung cancer cells $(28,36)$. In a rat acute lung injury model, overexpression of Prdx 1 increased the expression of proinflammatory cytokines interleukin-6 (IL-6), IL-8 and tumor necrosis factor- $\alpha$ (37). Inflammatory factors play an important role in the development of lung cancer. In addition, Prdx I affects the proliferation, migration and invasion of lung cancer cells by regulating various cytokines, in turn modulating different cell signaling pathways $(38,39)$. 


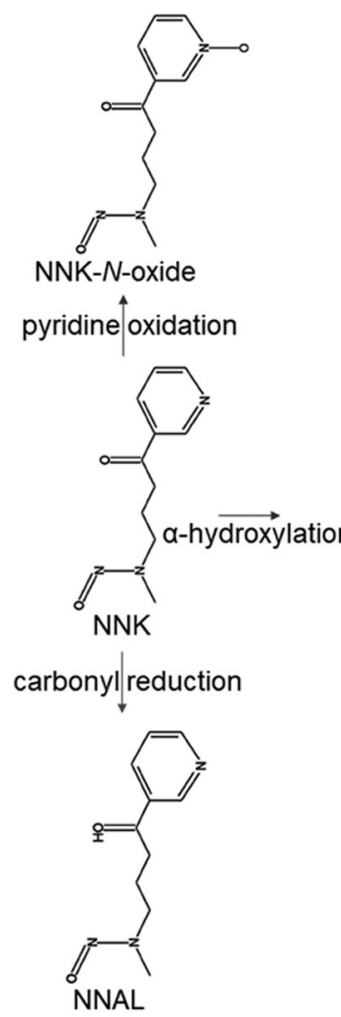

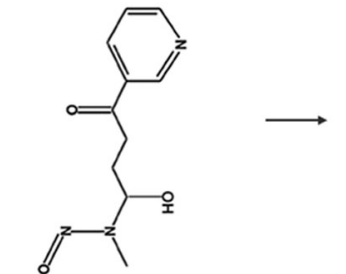

a-methylene hydroxyl-NNK

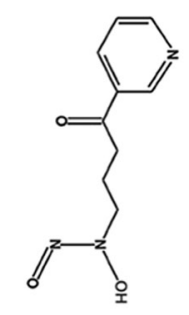

$\mathrm{CH}_{2}=\mathrm{O}$

a-hydroxymethyl-NNK
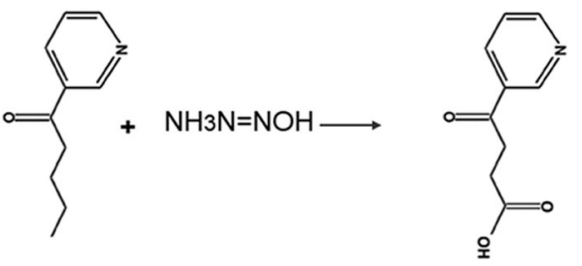

keto aldehyde

keto acid

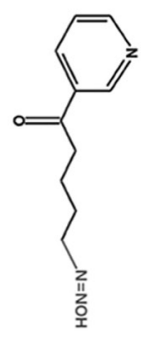

4-(3-pyridyl)-4-oxobutane1-diazohydroxide

Figure 1. Metabolic process of NNK, including three major metabolic methods of NNK: Carbonyl reduction, pyridine oxidation and $\alpha$-hydroxylation. Modified a previous study (7). NNK, NNK(4-(methylnitrosamino)-1-(3-pyridyl)-1-butanone); NNAL, NNAL(4-(methylnitrosamino)-1-(3-pyridyl)-1-butanol).

On one hand, Prdx 1 protects macromolecules, such as proteins and DNA, from oxidative damage and suppresses malignant transformation of normal cells, thus preventing tumor development. On the other hand, Prdx1 inhibits ROS-induced apoptosis of cancer cells and promotes tumor cell survival (27). Hence, understanding its mechanism of action may provide novel insights into the development of better therapeutic strategies for lung cancer.

PrdxI and NNK affect the growth and development of lung cancer by acting on P53 and K-Ras genes. NNK mainly undergoes metabolic activation through $\alpha$-methyl and $\alpha$-methylene hydroxylation, thereby producing DNA adducts and promoting cancer development. $\alpha$-methyl hydroxylated metabolites of NNK can pyridyloxobutylate DNA and produce DNA pyridyloxobutyl adducts, whereas $\alpha$-methylene hydroxylation generates $\alpha$-methylenehydroxy-NNK, methane diazohydroxide and methyldiazonium ions. These react with DNA and yield 7-methyl guanine, $\mathrm{O}^{6-}$ methyl guanine and $\mathrm{O}^{4}$-methyl thymine adducts (7). NNK induces oxidative stress by increasing the level of intracellular ROS, which in turn leads to the mutation of K-Ras and P53 oncogenes. In addition, the NNK metabolites have been shown to result in the mutation of K-Ras and P53 oncogenes in the lung. Thus, these deleterious effects of NNK on DNA may promote the development of lung cancer.

Prdx1 is considered a potential marker for NSCLC, and the interaction between Prdx1 and ROS plays an important role in the development of tumors (40). ROS plays a role in cell growth, differentiation, immune response and apoptosis $(41,42)$. Increase in intracellular levels of ROS activates the expression of P53 (15), which in turn induces the expression of apoptotic factors, such as Bak and Bax, under oxidative stress, promotes the activation of caspases and finally activates the mitochondrial apoptotic signaling pathway (27). P53 in its active form suppresses the proliferation of abnormal cells, thereby exerting a tumor suppressor effect (43). In addition, P53 plays an important role in detecting DNA damage. P53 status after reducing the expression of Prdx1 is the major determinant of tumor growth and response of lung cancer cells to treatment (15). K-Ras mutations are known to cause uncontrolled division of human lung adenocarcinoma cells (44-46). Furthermore, K-Ras mutations and ROS-induced oxidative stress are the major causes of NSCLC development. Prdx1 inhibits the activation of ROS/ERK/cyclin D1 pathway, thus results in $\mathrm{Nrf2}$-dependent inhibition of K-Ras-driven lung tumorigenesis (28).

NNK may promote lung cancer development by increasing the intracellular ROS level and inducing mutations in important oncogenes. Prdx1 effectively eliminates excess ROS and prevents gene mutations caused by oxidative damage of DNA. Prdx1 prevents the occurrence of mutations in the P53 gene, enabling it to detect and repair damaged DNA. Furthermore, activation of the Nrf2 pathway results in upregulation of Prdx1. Prdx1 inhibits the ROS/ERK/cyclin D1 signaling pathway and suppresses the development of lung tumors (Fig. 2) $(42,43,47,48)$.

Prdxl and NNK affect the growth and development of lung cancer by reacting with heme and hemoglobin. It has been demonstrated that NNK-induced DNA damage is significantly reduced by antioxidants (BHT), catalase and 


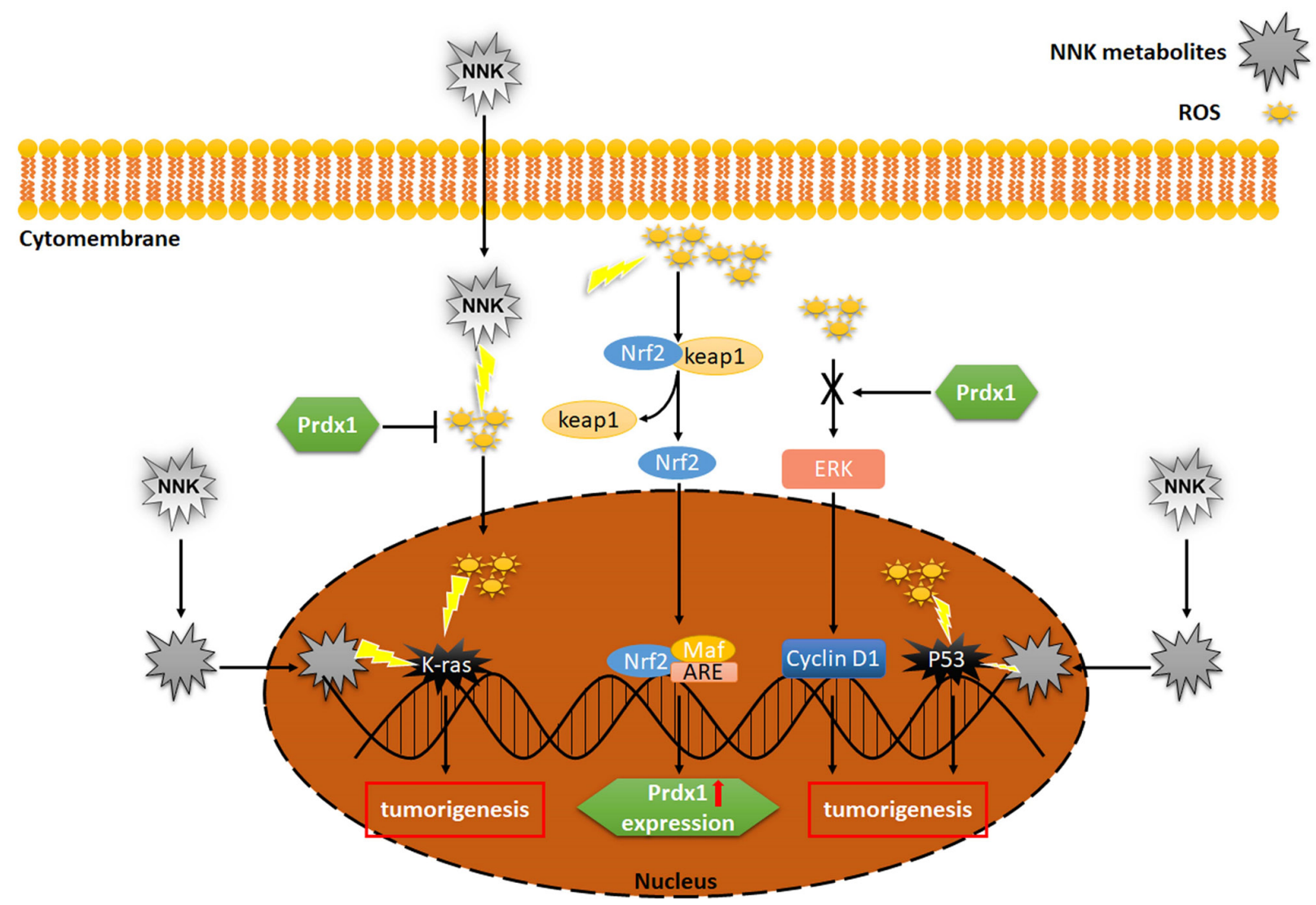

Figure 2. Effects of Prdx1 and NNK on P53 and K-Ras genes in lung cancer cells. NNK stimulates the production of ROS and Prdx1 scavenges ROS, which affects the development of lung cancer through DNA damage. Prdx1, peroxiredoxin I); NNK, 4-(methylnitrosamino)-1-(3-pyridyl)-1-butanone; Nrf2, nucleosome 2-related factor 2; ARE, antioxidant response element; ROS, reactive oxygen species; keap1, kelch-like ECH-associated protein-1.

superoxide dismutase (SOD) in A549 cells. The order of the effectiveness has been indicated to be BHT $>$ catalase $>$ SOD (8). Thus, it is speculated that NNK mainly induces generation of $\mathrm{H}_{2} \mathrm{O}_{2}(8,49,50)$. The $\alpha$-methyl hydroxylation of NNK results in the formation of unstable $\alpha$-hydroxymethyl NNK. The decomposition of a-hydroxymethyl NNK results in the formation of electrophilic 4-(3-pyridyl)-4-oxybutyl diazoxide, which can react with hemoglobin to form hemoglobin adduct $(7,51)$. NNK $\alpha$-methyl hydroxylation results in globulin methylation and pyridyloxybutylation (15), and the hemoglobin adduct formed by pyridyloxybutylation releases 4-hydroxy-1-(3-pyridyl)-1-butanone by alkaline hydrolysis (51). Studies have shown that keto alcohol-releasing adducts were formed by treatment of hemoglobin with NNK (51-53). Phenylethyl isothiocyanate treatment can significantly inhibit NNK-mediated lung tumorigenesis by reducing the release of ketone alcohol products (54).

Prdx1 can bind to heme (53), which is abundant in red blood cells. Furthermore, heme is widely distributed in organelles, such as the nucleus, endoplasmic reticulum and plasma membrane $(55,56)$, and it is involved in a processes in mammalian cells, including respiration, metabolism, transcription, DNA binding and protein degradation $(55,57)$. Heme is synthesized in mitochondria and loosely bound to Prdx1 (31), which is proposed to facilitate the transport of heme to other organelles $(55,56,58)$. Heme is insoluble in aqueous solutions and is toxic to the cells (59), and the toxicity is further manifested by the generation of ROS (57). However, binding of heme to Prdx1 reduces heme toxicity and promotes $\mathrm{H}_{2} \mathrm{O}_{2}$-mediated heme degradation (60). Thus, $\mathrm{Prdx} 1$ protects free heme from peroxidation but loses its peroxidase activity when bound to heme (31). NNK induces the generation $\mathrm{H}_{2} \mathrm{O}_{2}$ and Prdx1 is more sensitive to $\mathrm{H}_{2} \mathrm{O}_{2} \cdot \mathrm{H}_{2} \mathrm{O}_{2}$ causes erythrocyte lysis, leading to the release of large amounts of heme and hemoglobin (61). Heme interacts with oxygen to produce ROS (62), which further destroys red blood cells. The binding of heme and Prdx1 reduces heme cytotoxicity; however, Prdx1 loses its ROS scavenging ability. NNK metabolites produce adducts with hemoglobin, thereby promoting the development of lung tumors, and Prdx1 plays a role in ROS scavenging, which in turn protects red blood cells from oxidative damage and inhibits lung tumorigenesis (Fig. 3).

Prdxl and NNK affect the growth and development of lung cancer by acting on alveolar macrophages (AMs) and NK cells. NNK metabolites inhibit AM-mediated production of interleukin-12 (IL-12), nitric oxide and TNF; however, they also induce the production of IL-10 (63), which may promote the growth and development of lung tumors (64). Additionally, NNK has an inhibitory effect on TNF-dependent cytotoxicity of AMs (49). Furthermore, metabolites produced by NNK $\alpha$-methyl hydroxylation may be involved in the regulation of AM function. For example, keto acid inhibits IL-12 production by AMs, while keto alcohol may inhibit the AM production of TNF and IL-12 (65). NNK may induce the expression of cyclooxygenase $2(C O X-2)$ and upregulate prostaglandin E2 


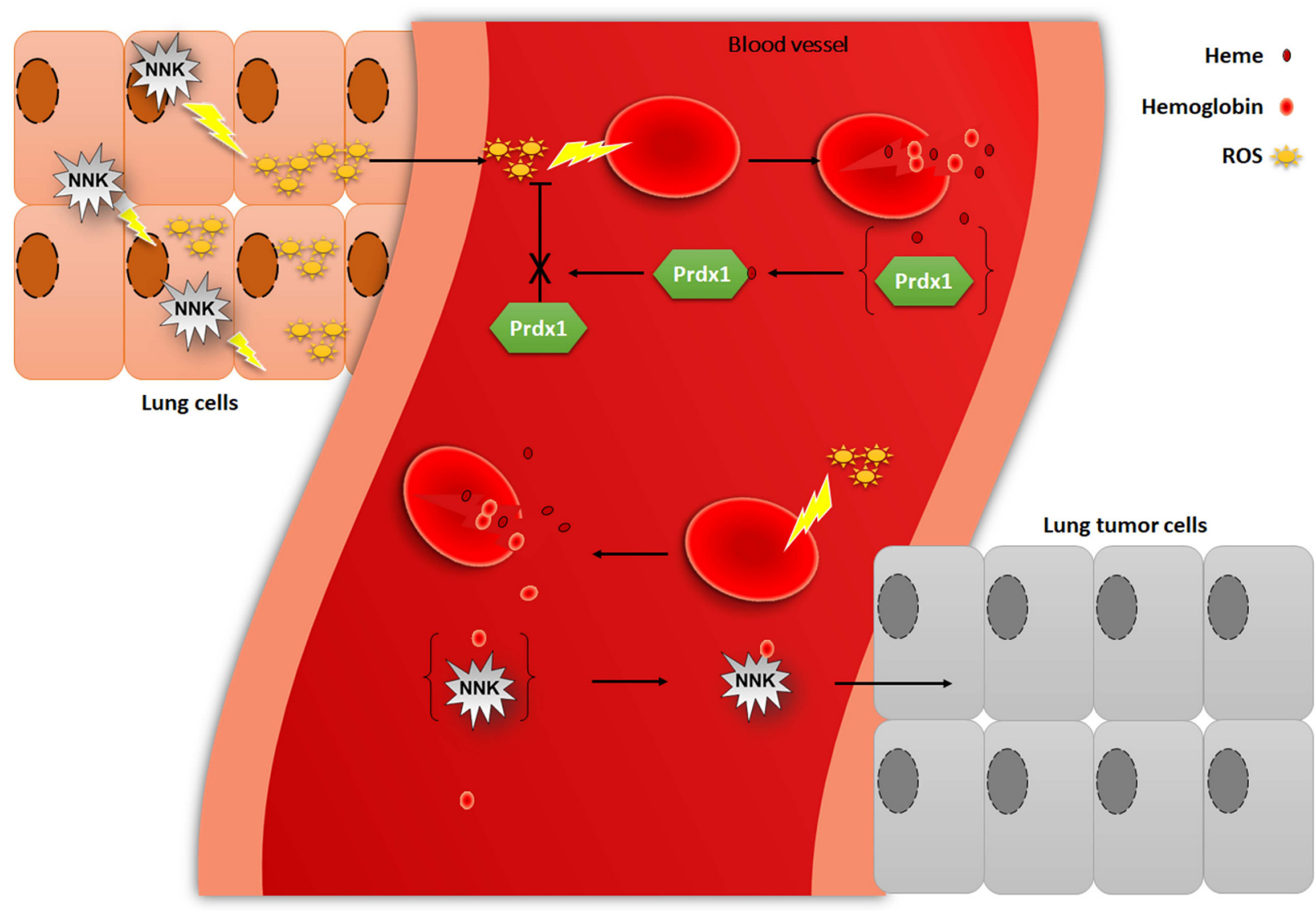

Figure 3. Effects of Prdx1 and NNK on heme and hemoglobin in lung cancer cells. In the blood, NNK interacts with hemoglobin, Prdx1 interacts with heme and they jointly affect the occurrence and development of lung cancer. Prdx1, peroxiredoxin I; NNK, 4-(methylnitrosamino)-1-(3-pyridyl)-1-butanone; ROS, reactive oxygen species.

(PGE2); PGE2 in turn upregulates IL-10 $(63,66)$. Nicotinic acetylcholine receptors (nAChRs) are present in immune cells (67), and NNK has high affinity towards nAChRs. Thus, interaction of NNK and nAChRs may activate the production of IL-10 (68). Moreover, IL-10 suppresses the production of IL-12 (69), and inhibition of IL-12 leads to decreased expression of interferon- $\gamma(70,71)$. Furthermore, IL-12 is mainly produced by phagocytes (monocytes/macrophages and neutrophils) and dendritic cells (72) and enhances the cytotoxicity of AM and NK cells (73). NK cells are a group of lymphocytes that can kill tumor cells (74). Therefore, it can be speculated that NNK attenuates the toxic effects of NK cells on tumor cells and further promotes the development of lung cancer.

All six Prdxs are expressed by human lung cells; however, AMs mainly express Prdx1 and III (75). Prdx1 may affect the production of pro-inflammatory cytokines in macrophages (76) and has the ability to enhance NK cell toxicity in vitro. Furthermore, it has been reported that free thiol groups are required to maintain NK cell toxicity against tumor cells (42). The alkylation of free sulfhydryl groups in Prdx1 upon reduction decreases its ability to enhance NK cell toxicity, further indicating the requirement of free thiol groups for enhanced cytotoxicity of NK cells (16). Therefore, Prdx1 not only protects the cells from oxidative damage, but also selectively promotes the killing effect of AM and NK cells in certain tumors.
NNK may activate AMs to produce $\mathrm{H}_{2} \mathrm{O}_{2}$. NNK inhibits the production of IL-12 and TNF by AMs, thereby reducing the cytotoxicity of AMs and NKs against the tumor cells. Prdx1 is expressed mainly in AMs and may play a role in immune regulation by affecting inflammatory factors. Prdx1 may inhibit lung tumors by enhancing the killing effect of NK cells. However, the exact role of NNK and Prdx1 in AM-mediated killing of tumor cells is still unclear (Fig. 4) (64,70,74-76).

Prdxl and NNK affect EMT. Long-term exposure of lung alveolar cells to NNK results in their proliferation and eventually malignant transformation (77). After the cells are exposed to NNK, the expression of intracellular $\beta$-catenin and F-actin decrease, whereas that of fibronectin, vimentin and matrix metalloproteinase-2 increase. This in turn promotes EMT (77). EMT is a process by which epithelial cells are transformed into the mesenchymal phenotype, which increases their invasion and migration capabilities. Morphologically, the epithelial cells are loosely connected and the cytoskeleton structure is reorganized. The EMT process is accompanied by various changes in protein expression, including a decrease in E-cadherin and an increase in fibronectin expression levels (77). Low E-cadherin expression decreases cell adhesion, and downregulation of E-cadherin is also considered as a sign of EMT (78). NNK and ROS induce EMT through different signaling pathways (79). In cancer cells, NNK may promote the production of ROS, such as $\mathrm{H}_{2} \mathrm{O}_{2}$, which in turn 


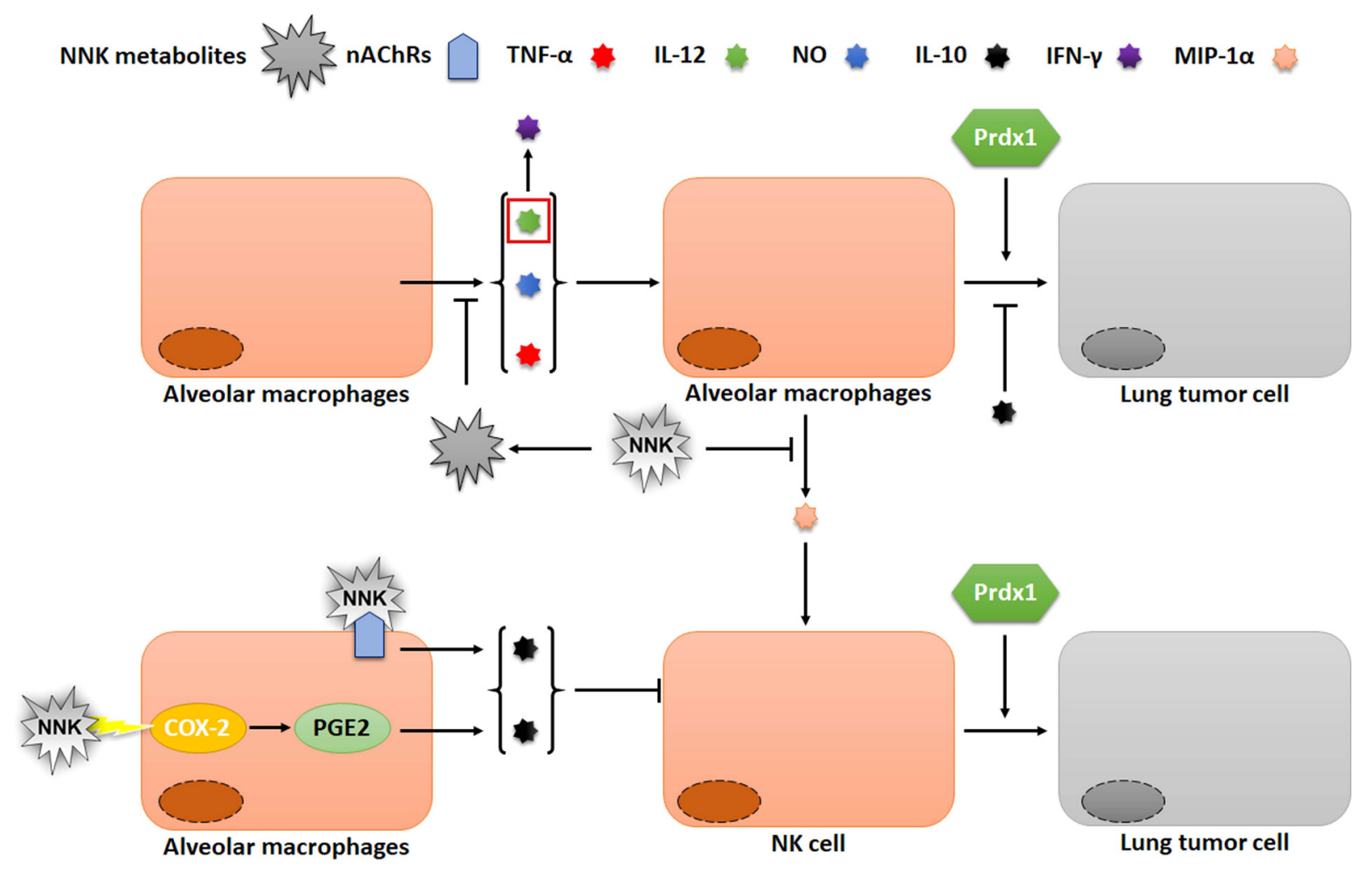

Figure 4. Effects of Prdx1 and NNK on AM and NK cells. NNK can reduce the toxicity of AM and NK cells to lung cancer cells, while Prdx1 can stimulate NK cells to kill lung cancer cells. Prdx1, peroxiredoxin I; NNK, 4-(methylnitrosamino)-1-(3-pyridyl)-1-butanone; AM, alveolar macrophages; NK, natural killer cells; IL, interleukin; nAChRs, nicotinic acetylcholine receptors; MIP, macrophage inflammatory protein; PGE2, prostaglandin E2; COX, cyclooxygenase.

activates c-Src $(80,81)$, leading to cytoskeletal modifications (79) and initiation of EMT (82). Most tissues usually do not express $C O X-2$ or express it at a low level (83). The induced expression of $C O X-2$ inhibits apoptosis and increases the migration potential of cancer cells (84). The combination of NNK and a7-nAChR can induce the expression of $C O X-2$, which upregulates fibronectin and promotes EMT (79).

Furthermore, Prdx1 is a type of peroxidase reductase, which can play the role of scavenging ROS, thus inhibiting the EMT process. It has been observed that Prdx 1 can promote EMT in breast (85), pancreatic (86) and colon cancer (87). Furthermore, high expression levels of Prdx1 downregulates E-cadherin, whereas, at lower levels it upregulates E-cadherin in A549 lung adenocarcinoma cells (88). TGF- $\beta 1$ is a pleiotropic cytokine that is involved in apoptosis, differentiation and proliferation of cells and is the primary inducer of EMT (83,89-91). It has been shown that the overexpression of Prdx1 in lung cancer cells significantly enhances TGF- $\beta 1$-mediated EMT and cell migration (92).

In A549 lung cancer cells, NNK treatment results in a significant increase in Prdx1 expression. NNK not only results in ROS production, but also upregulates the expression of fibronectin via COX-2 and promotes EMT. Prdx1 can play a role in scavenging ROS, and Prdx1 can also inhibit EMT process by scavenging ROS caused by NNK. Additionally, high levels of Prdx1 results in upregulation of E-cadherin, which promotes EMT (Fig. 5) (77-82,84,85).

Signaling pathways associated with Prdxl and NNK in lung cancer cells. NADPH oxidase of Nox family is expressed in both normal and cancer cells, and is related to ROS production and tumorigenicity in various cancer cells. For example, Nox1 is highly expressed in human colon cancer and prostate cancer, and lung cancer A549 cells also express Nox1, 2 and $4(16,93)$. NNK induces the expression of NOX protein and results in the production of large amount of ROS, which causes damage to protein and DNA through oxidative stress. In A549 lung cancer cells, NNK-mediated generation of ROS through NOX activates phosphatidylinositol-3-kinase (PI3K)/protein kinase B (AKT) and Wnt signaling pathways, which leads to the development of drug resistance in lung cancer cells (16) and is associated with lower survival rate of patients with stage 1 lung tumors in Tumor-Node-Metastasis staging system (94). NNK increases the expression of thromboxane A2 (TxA2) and Tx receptor in lung cancer cells by elevating COX and Tx synthase expression (95). NNK has been shown to promote adhesion and invasion of CL1.0 cells through $\alpha 7-n$ AChR/ERK/Contactin 1 signaling (96). Furthermore, NNK prevents $\mathrm{PH}$ domain leucine-rich repeat-containing protein phosphatase 2-mediated AKT dephosphorylation, activates AKT to inhibit E-cadherin expression and promotes lung cancer cell migration (97). The combination of NNK and $\alpha 7-n A C h R s$ activates c-Src and protein kinase $\mathrm{C}$, and promotes the dissociation of phosphorylated Bad from Bcl-xl, which in turn inhibits apoptosis (98).

In tumor cells, Prdx1 has been reported to eliminate large quantities of ROS produced by tumor cell metabolism and thus, suppresses tumor cell death. Additionally, Prdx1 inhibits the oxidative stress-induced PI3K/AKT signaling pathway by eliminating ROS. It is known that the ROS-induced activation 


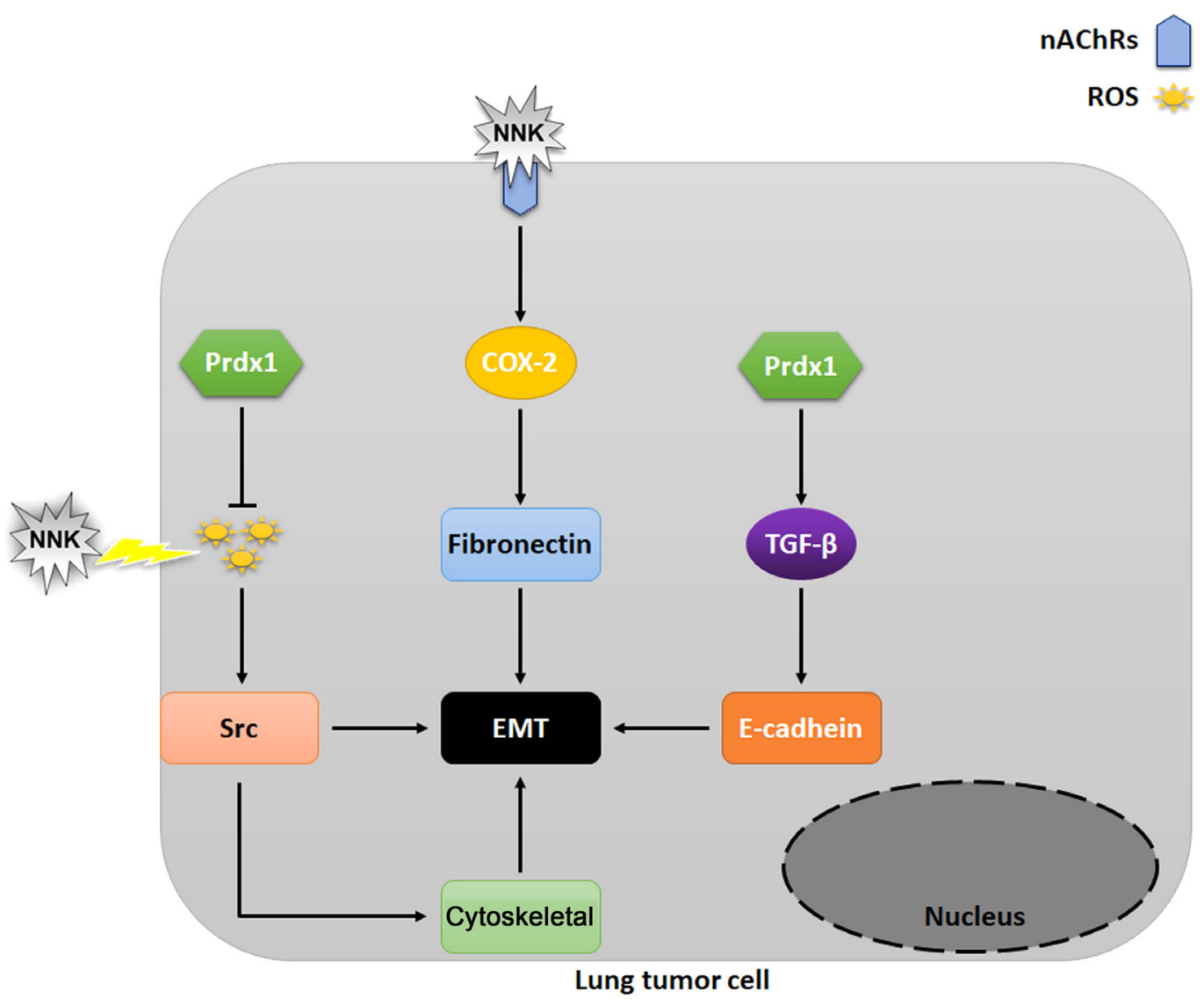

Figure 5. Effects of Prdx1 and NNK on EMT of A549 lung cancer cells. In lung cancer cells, NNK can promote EMT process, Prdx1 can inhibit EMT process by scavenging ROS, but high level of Prdx1 can promote EMT process. Prdx1, peroxiredoxin I; NNK, 4-(methylnitrosamino)-1-(3-pyridyl)-1-butanone; EMT, epithelial-mesenchymal transition; nAChRs, nicotinic acetylcholine receptors; ROS, reactive oxygen species; COX, cyclo-oxygenase.

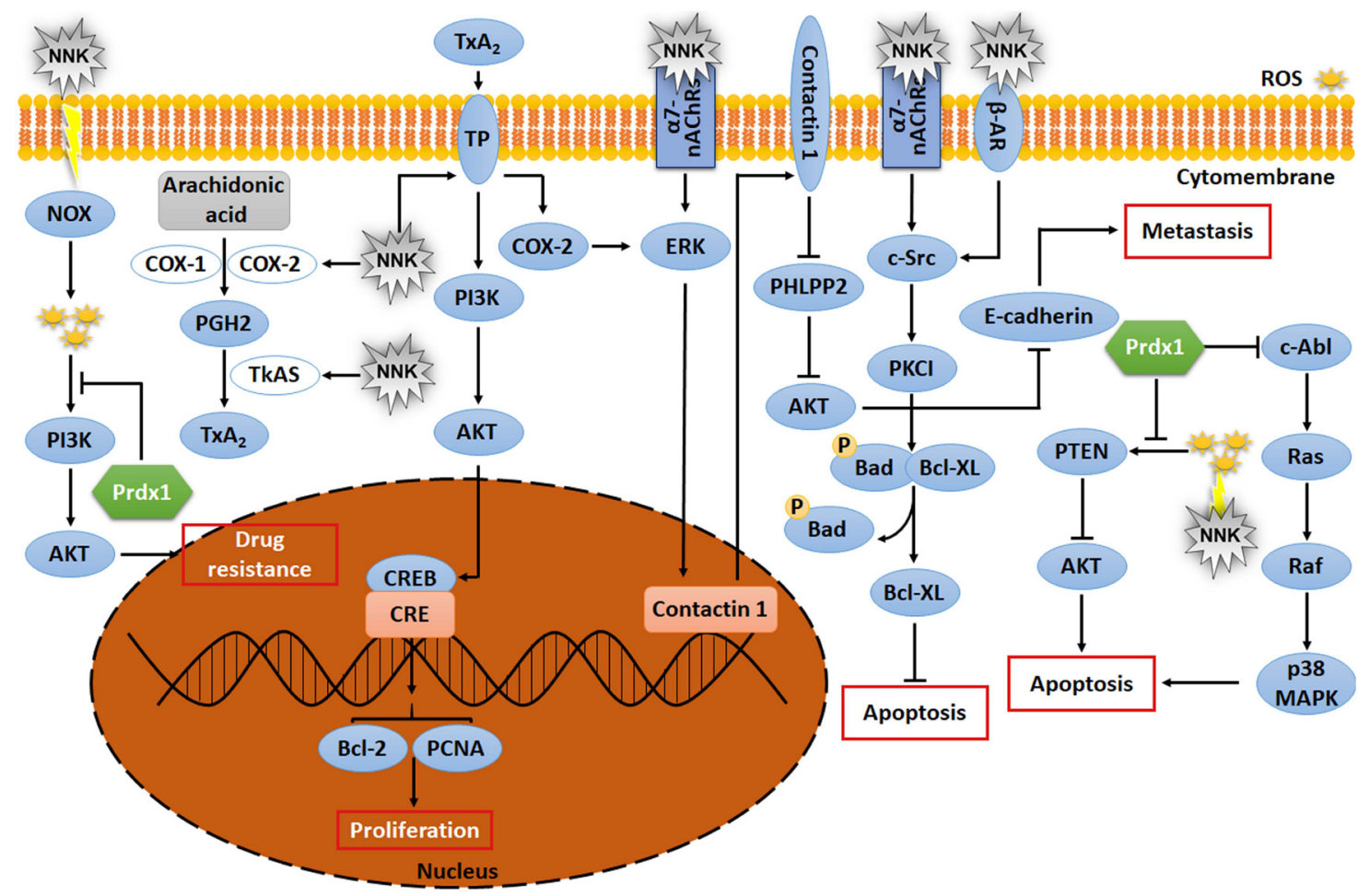

Figure 6. Signaling pathway of Prdx1 and NNK. NNK and Prdx1 are involved in the regulation of signaling pathways in the development of lung cancer cells. NOX, NADPH oxidase; TxA 2 , thromboxane A2; PGH2, prostaglandin H2; COX, cyclooxygenase; NNK, 4-(methylnitrosamino)-1-(3-pyridyl)-1-butanone; TP, thromboxane receptor; PCNA, proliferating cell nuclear antigen; CREB, cyclic AMP response element-binding protein; CRE, cyclic AMP response element; ROS, reactive oxygen species; PHLPP2, pleckstrin homology domain leucine-rich repeat protein phosphatase 2; PKCI, protein kinase C interacting protein. 
of PI3K/AKT is due to the oxidative inactivation of phosphatase and tensin homolog (PTEN) protein (99). Furthermore, Prdx1 protects PTEN lipid phosphatase activity from oxidative inactivation, thereby preventing AKT from driving tumor cell proliferation and inducing apoptosis (26). C-Abl plays a vital role in oxidative stress-induced cell death (100). Prdx1 can be used as a physiological inhibitor of C-Abl (18) to inhibit apoptosis induced by the C-Abl/P38/MAPK signaling pathway.

NNK induces Nox protein to produce ROS, and activates the PI3K/Akt signaling pathway; however, NNK inhibits the same pathway by removing ROS or preventing oxidative inactivation of phosphatase and PTEN. In addition, NNK activates $\alpha 7-n A C h R s$ and downstream signaling pathways, and hence promotes apoptosis and migration of lung cancer cells. Furthermore, both NNK and Prdx1 can regulate apoptosis-related proteins and thus, control the apoptosis of lung cancer cells $(99,101-103)$ (Fig. 6).

\section{Conclusions}

In conclusion, on the one hand, Prdx1 has the ability to protect erythrocytes and DNA from NNK-induced oxidative damage, prevent malignant transformation of cells and promote cytotoxicity of NK cells, suppressing tumor formation. In addition, Prdx1 prevents NNK-induced generation of large amount of ROS and hence, ROS-induced apoptosis, and promotes tumor cell survival. On the other hand, together with NNK, Prdx1 promotes EMT and migration of lung tumor cells. The signaling pathways of NNK and Prdx1 in lung cancer cells are intricate, and the associated mechanisms are yet to be explored.

\section{Acknowledgments}

Not applicable.

\section{Funding}

This research was supported by the Basic Science Research Program through the National Research Foundation of Korea funded by the Ministry of Education (grant no. 2020R1I1A2052417), The Korean Research Institute of Bioscience and Biotechnology Research Information System (grant no. RBM0112112) and The Project of Sanzong (grant no. ZRCPY202030) by Heilongjiang Bayi Agricultural University.

\section{Availability of data and materials}

Data sharing is not applicable to this article, as no datasets were generated or analyzed during the current study.

\section{Authors' contributions}

HNS, CXR, YXG and TK conceived and designed the review. HNS, CXR, YXG, DPX and TK wrote the manuscript and prepared the figures. HNS and TK reviewed and edited the manuscript. TK acquired the funding. All authors read and approved the final manuscript.

\section{Ethics approval and consent to participate}

Not applicable.

\section{Patient consent for publication}

Not applicable.

\section{Competing interests}

The authors declare that they have no competing interests.

\section{References}

1. Proctor RN: Tobacco and the global lung cancer epidemic. Nat Rev Cancer 1: 82-86, 2001.

2. Thun M, Peto R, Boreham J and Lopez AD: Stages of the cigarette epidemic on entering its second century. Tob Control 21: 96-101, 2012.

3. Bray F, Ferlay J, Soerjomataram I, Siegel RL, Torre LA and Jemal A: Global cancer statistics 2018: GLOBOCAN estimates of incidence and mortality worldwide for 36 cancers in 185 countries. CA Cancer J Clin 68: 394-424, 2018.

4. Witschi H: Carcinogenic activity of cigarette smoke gas phase and its modulation by beta-carotene and $\mathrm{N}$-acetylcysteine. Toxicol Sci 84: 81-87, 2005.

5. Jin Z, Gao F, Flagg T and Deng X: Tobacco-specific nitrosamine 4-(methylnitrosamino)-1-(3-pyridyl)-1-butanone promotes functional cooperation of $\mathrm{Bcl} 2$ and $\mathrm{c}-\mathrm{Myc}$ through phosphorylation in regulating cell survival and proliferation. J Biol Chem 279: 40209-40219, 2004.

6. Maser E: Significance of reductases in the detoxification of the tobacco-specific carcinogen NNK. Trends Pharmacol Sci 25: 235-237, 2004.

7. Yalcin E and de la Monte S: Tobacco nitrosamines as culprits in disease: Mechanisms reviewed. J Physiol Biochem 72: 107-120, 2016.

8. Yeh SL, Wang WY, Huang CS and Hu ML: Flavonoids suppresses the enhancing effect of beta-carotene on DNA damage induced by 4-(methylnitrosamino)-1-(3-pyridyl)-1-butanone (NNK) in A549 cells. Chem Biol Interact 160: 175-182, 2006.

9. Lehtonen ST, Svensk AM, Soini Y, Pääkkö P, Hirvikoski P, Kang SW, Säily M and Kinnula VL: Peroxiredoxins, a novel protein family in lung cancer. Int J Cancer 111: 514-521, 2004.

10. Gorrini C, Harris IS and Mak TW: Modulation of oxidative stress as an anticancer strategy. Nat Rev Drug Discov 12: 931-947, 2013.

11. Rhee SG and Kil IS: Multiple functions and regulation of mammalian peroxiredoxins. Annu Rev Biochem 86: 749-775, 2017.

12. Bajor M, Zych AO, Graczyk-Jarzynka A, Muchowicz A, Firczuk M, Trzeciak L, Gaj P, Domagala A, Siernicka M, Zagozdzon A, et al: Targeting peroxiredoxin 1 impairs growth of breast cancer cells and potently sensitises these cells to prooxidant agents. Br J Cancer 119: 873-884, 2018.

13. Han YH, Zhang YQ, Jin MH, Jin YH, Qiu MY, Li WL, He C, Yu LY, Hyun JW, Lee J, et al: Peroxiredoxin I deficiency increases keratinocyte apoptosis in a skin tumor model via the ROS-p38 MAPK pathway. Biochem Biophys Res Commun 529: 635-641, 2020.

14. Hampton MB, Vick KA, Skoko JJ and Neumann CA: Peroxiredoxin involvement in the initiation and progression of human cancer. Antioxid Redox Signal 28: 591-608, 2018.

15. Chen MF, Chen WC, Wu CT, Lin PY, Shau H, Liao SK, Yang CT and Lee KD: p53 status is a major determinant of effects of decreasing peroxiredoxin I expression on tumor growth and response of lung cancer cells to treatment. Int J Radiat Oncol Biol Phys 66: 1461-1472, 2006.

16. Hirata N, Yamada S, Sekino Y and Kanda Y: Tobacco nitrosamine NNK increases ALDH-positive cells via ROS-Wnt signaling pathway in A549 human lung cancer cells. J Toxicol Sci 42: 193-204, 2017.

17. Shi GQ, Zhou WS, Li M, Ren F and Han YW: Characterization and expression analysis of peroxiredoxin genes in NNK-induced V79 cells. Biomed Environ Sci 30: 224-228, 2017. 
18. Immenschuh S and Baumgart-Vogt E: Peroxiredoxins, oxidative stress, and cell proliferation. Antioxid Redox Signal 7: 768-777, 2005.

19. Akopyan $\mathrm{G}$ and Bonavida B: Understanding tobacco smoke carcinogen $\mathrm{NNK}$ and lung tumorigenesis. Int J Oncol 29: 745-752, 2006

20. Hecht SS, Hochalter JB, Villalta PW and Murphy SE: 2'-Hydroxylation of nicotine by cytochrome P450 2A6 and human liver microsomes: Formation of a lung carcinogen precursor. Proc Natl Acad Sci USA 97: 12493-12497, 2000.

21. Peterson LA: Context matters: Contribution of specific DNA adducts to the genotoxic properties of the tobacco-specific nitrosamine NNK. Chem Res Toxicol 30: 420-433, 2017.

22. Ashmore JH, Luo S, Watson CJW and Lazarus P: Carbonyl reduction of NNK by recombinant human lung enzymes: Identification of HSD17 312 as the reductase important in (R)-NNAL formation in human lung. Carcinogenesis 39: 1079-1088, 2018.

23. Leslie EM, Ghibellini G, Nezasa $K$ and Brouwer KL: Biotransformation and transport of the tobacco-specific carcinogen 4-(methylnitrosamino)-1-(3-pyridyl)-1-butanone (NNK) in bile duct-cannulated wild-type and Mrp2/Abcc2-deficient (TR) Wistar rats. Carcinogenesis 28: 2650-2656, 2007.

24. Richter E, Friesenegger S, Engl J and Tricker AR: Use of precision-cut tissue slices in organ culture to study metabolism of 4-(methylnitrosamino)-1-(3-pyridyl)-1-butanone (NNK) and 4-(methylnitrosamino)-1-(3-pyridyl)-1-butanol (NNAL) by hamster lung, liver and kidney. Toxicology 144: 83-91, 2000.

25. Rhee SG, Kang SW, Chang TS, Jeong W and Kim K: Peroxiredoxin, a novel family of peroxidases. IUBMB Life 52: 35-41, 2001.

26. Neumann CA, Cao J and Manevich Y: Peroxiredoxin 1 and its role in cell signaling. Cell Cycle 8: 4072-4078, 2009.

27. Ding C, Fan $X$ and Wu G: Peroxiredoxin 1-an antioxidant enzyme in cancer. J Cell Mol Med 21: 193-202, 2017.

28. Park YH, Kim SU, Lee BK, Kim HS, Song IS, Shin HJ, Han YH, Chang KT, Kim JM, Lee DS, et al: Prx I suppresses K-ras-driven lung tumorigenesis by opposing redox-sensitive ERK/cyclin D1 pathway. Antioxid Redox Signal 19: 482-496, 2013.

29. Chang TS, Jeong W, Choi SY, Yu S, Kang SW and Rhee SG: Regulation of peroxiredoxin I activity by Cdc2-mediated phosphorylation. J Biol Chem 277: 25370-25376, 2002.

30. Poole LB: The basics of thiols and cysteines in redox biology and chemistry. Free Radic Biol Med 80: 148-157, 2015.

31. Watanabe Y, Ishimori K and Uchida T: Dual role of the active-center cysteine in human peroxiredoxin 1: Peroxidase activity and heme binding. Biochem Biophys Res Commun 483 930-935, 2017.

32. Gozzelino R, Jeney V and Soares MP: Mechanisms of cell protection by heme oxygenase-1. Annu Rev Pharmacol Toxicol 50: 323-354, 2010

33. Guo Y, Patil NK, Luan L, Bohannon JK and Sherwood ER: The biology of natural killer cells during sepsis. Immunology 153 190-202, 2018

34. Aktas ON, Öztürk AB, Erman B, Erus S, Tanju S and Dilege S: Role of natural killer cells in lung cancer. J Cancer Res Clin Oncol 144: 997-1003, 2018

35. Li S, Wang R, Zhang M, Wang $\mathrm{L}$ and Cheng S: Proteomic analysis of non-small cell lung cancer tissue interstitial fluids. World J Surg Oncol 11: 173, 2013.

36. Chen MF, Keng PC, Shau H, Wu CT, Hu YC, Liao SK and Chen WC: Inhibition of lung tumor growth and augmentation of radiosensitivity by decreasing peroxiredoxin I expression. Int J Radiat Oncol Biol Phys 64: 581-591, 2006.

37. Liu D, Mao P, Huang Y, Liu Y, Liu X, Pang X and Li Y: Proteomic analysis of lung tissue in a rat acute lung injury model: Identification of PRDX1 as a promoter of inflammation. Mediators Inflamm 2014: 469358, 2014.

38. Brenner DR, Fanidi A, Grankvist K, Muller DC, Brennan P Manjer J, Byrnes G, Hodge A, Severi G, Giles GG, et al: Inflammatory cytokines and lung cancer risk in 3 prospective studies. Am J Epidemiol 185: 86-95, 2017.

39. DeCotiis C, Hu Y, Greenberg AK, Huie M, Tsay JC, Pass H, Goldberg JD and Rom WN: Inflammatory cytokines and non-small cell lung cancer in a CT-scan screening cohort: Background review of the literature. Cancer Biomark 16 219-233, 2016

40. Chang JW, Lee SH, Jeong JY, Chae HZ, Kim YC, Park ZY and Yoo YJ: Peroxiredoxin-I is an autoimmunogenic tumor antigen in non-small cell lung cancer. FEBS Lett 579: 2873-2877, 2005.

41. Finkel T and Holbrook NJ: Oxidants, oxidative stress and the biology of ageing. Nature 408: 239-247, 2000.
42. Moloney JN and Cotter TG: ROS signalling in the biology of cancer. Semin Cell Dev Biol 80: 50-64, 2018.

43. Macip S, Igarashi M, Berggren P, Yu J, Lee SW and Aaronson SA Influence of induced reactive oxygen species in p53-mediated cell fate decisions. Mol Cell Biol 23: 8576-8585, 2003.

44. Moll HP, Pranz K, Musteanu M, Grabner B, Hruschka N, Mohrherr J, Aigner P, Stiedl P, Brcic L, Laszlo V, et al: Afatinib restrains K-RAS-driven lung tumorigenesis. Sci Transl Med 10: eaao2301, 2018.

45. Aran V and Omerovic J: Current approaches in NSCLC targeting K-RAS and EGFR. Int J Mol Sci 20: 5701, 2019.

46. Scheffler M, Ihle MA, Hein R, Merkelbach-Bruse S, Scheel AH, Siemanowski J, Brägelmann J, Kron A, Abedpour N, Ueckeroth F, et al: K-ras mutation subtypes in NSCLC and associated Co-occuring mutations in other oncogenic pathways. J Thorac Oncol 14: 606-616, 2019.

47. Peeper DS, Upton TM, Ladha MH, Neuman E, Zalvide J, Bernards R, DeCaprio JA and Ewen ME: Ras signalling linked to the cell-cycle machinery by the retinoblastoma protein. Nature 386: 177-181, 1997.

48. Slebos RJ, Kibbelaar RE, Dalesio O, Kooistra A, Stam J, Meijer CJ, Wagenaar SS, Vanderschueren RG, van Zandwijk N, Mooi WJ, et al: K-ras oncogene activation as a prognostic marker in adenocarcinoma of the lung. N Engl J Med 323: 561-565, 1990

49. Proulx LI, Paré G and Bissonnette EY: Alveolar macrophage cytotoxic activity is inhibited by 4-(methylnitrosamino)-1-(3-py ridyl)-1-butanone (NNK), a carcinogenic component of cigarette smoke. Cancer Immunol Immunother 56: 831-838, 2007.

50. Rioux $\mathrm{N}$ and Castonguay A: The induction of cyclooxygenase-1 by a tobacco carcinogen in U937 human macrophages is correlated to the activation of NF-kappaB. Carcinogenesis 21: $1745-1751,2000$

51. Wang Y, Narayanapillai SC, Hu Q, Fujioka N and Xing C: Detection and quantification of 4-hydroxy-1-(3-pyridyl)-1-butanone (HPB) from smoker albumin and its potential as a surrogate biomarker of tobacco-specific nitrosamines exposure and bioactivation. Toxicol Lett 311: 11-16, 2019.

52. Peterson LA, Carmella SG and Hecht SS: Investigations of metabolic precursors to hemoglobin and DNA adducts of 4-(meth ylnitrosamino)-1-(3-pyridyl)-1-butanone. Carcinogenesis 11: 1329-1333, 1990.

53. Hecht SS, Stepanov I and Carmella SG: Exposure and metabolic activation biomarkers of carcinogenic tobacco-specific nitrosamines. Acc Chem Res 49: 106-114, 2016.

54. Hecht SS, Trushin N, Rigotty J, Carmella SG, Borukhova A, Akerkar S, Desai D, Amin S and Rivenson A: Inhibitory effects of 6-phenylhexyl isothiocyanate on 4-(methylnitrosamino)-1-(3pyridyl)-1-butanone metabolic activation and lung tumorigenesis in rats. Carcinogenesis 17: 2061-2067, 1996.

55. Tsiftsoglou AS, Tsamadou AI and Papadopoulou LC: Heme as key regulator of major mammalian cellular functions: Molecular, cellular, and pharmacological aspects. Pharmacol Ther 111: 327-345, 2006

56. Severance $S$ and Hamza I: Trafficking of heme and porphyrins in metazoa. Chem Rev 109: 4596-4616, 2009.

57. Shimizu T, Lengalova A, Martínek V and Martínková M: Heme: Emergent roles of heme in signal transduction, functional regulation and as catalytic centres. Chem Soc Rev 48: 5624-5657, 2019.

58. Khan AA and Quigley JG: Control of intracellular heme levels: Heme transporters and heme oxygenases. Biochim Biophys Acta 1813: 668-682, 2011.

59. Roumenina LT, Rayes J, Lacroix-Desmazes S and Dimitrov JD: Heme: Modulator of plasma systems in hemolytic diseases. Trends Mol Med 22: 200-213, 2016.

60. Vlasova II: Peroxidase activity of human hemoproteins: Keeping the fire under control. Molecules 23: 2561, 2018.

61. Peralta IN, Cogoi L, Filip R and Anesini C: Prevention of hydrogen peroxide-induced red blood cells lysis by Ilex paraguariensis aqueous extract: Participation of phenolic and xanthine compounds. Phytother Res 27: 192-198, 2013

62. Hahl P, Hunt R, Bjes ES, Skaff A, Keightley A and Smith A Identification of oxidative modifications of hemopexin and their predicted physiological relevance. J Biol Chem 292: 13658-13671, 2017.

63. Therriault MJ, Proulx LI, Castonguay A and Bissonnette EY: Immunomodulatory effects of the tobacco-specific carcinogen, NNK, on alveolar macrophages. Clin Exp Immunol 132: 232-238, 2003

64. Liu Y and Cao X: The origin and function of tumor-associated macrophages. Cell Mol Immunol 12: 1-4, 2015. 
65. Proulx LI, Castonguay A and Bissonnette EY: Cytokine production by alveolar macrophages is down regulated by the alpha-methylhydroxylation pathway of 4-(methylnitrosamino)1-(3-pyridyl)-1-butanone (NNK). Carcinogenesis 25: 997-1003, 2004.

66. Proulx LI,Gaudreault M,TurmelV,AugustoLA,Castonguay A and BissonnetteEY:4-(Methylnitrosamino)-1-(3-pyridyl)-1-butanone, a component of tobacco smoke, modulates mediator release from human bronchial and alveolar epithelial cells. Clin Exp Immunol 140: 46-53, 2005

67. Mashimo M: Dual roles of $\alpha 7$ nicotinic acetylcholine receptors expressed in immune cells in T cell differentiation- $\alpha 7$ nAChRs exert different actions between antigen-presenting cells and CD4(+) T cells. Yakugaku Zasshi 140: 1421-1425, 2020 (In Japanese).

68. Schuller HM, Jull BA, Sheppard BJ and Plummer HK: Interaction of tobacco-specific toxicants with the neuronal alpha(7) nicotinic acetylcholine receptor and its associated mitogenic signal transduction pathway: Potential role in lung carcinogenesis and pediatric lung disorders. Eur J Pharmacol 393: 265-277, 2000.

69. Rahim SS, Khan N, Boddupalli CS, Hasnain SE and Mukhopadhyay S: Interleukin-10 (IL-10) mediated suppression of IL-12 production in RAW 264.7 cells also involves c-rel transcription factor. Immunology 114: 313-321, 2005.

70. Zirnheld AL, Villard M, Harrison AM, Kosiewicz MM and Alard P: $\beta$-Catenin stabilization in NOD dendritic cells increases IL-12 production and subsequent induction of IFN- $\gamma$-producing T cells. J Leukoc Biol 106: 1349-1358, 2019.

71. Chakraborty K, Zhou Z, Wakamatsu N and Guerrero-Plata A Interleukin-12p40 modulates human metapneumovirus-induced pulmonary disease in an acute mouse model of infection. PLoS One 7: e37173, 2012.

72. Guo Y, Cao W and Zhu Y: Immunoregulatory functions of the IL-12 family of cytokines in antiviral systems. Viruses 11: 772, 2019.

73. Trinchieri G: Interleukin-12 and the regulation of innate resistance and adaptive immunity. Nat Rev Immunol 3: 133-146, 2003

74. Caligiuri MA: Human natural killer cells. Blood 112: 461-469, 2008

75. Kinnula VL, Lehtonen S, Kaarteenaho-Wiik R, Lakari E, Pääkkö P, Kang SW, Rhee SG and Soini Y: Cell specific expression of peroxiredoxins in human lung and pulmonary sarcoidosis. Thorax 57: 157-164, 2002.

76. Tae Lim Y, Sup Song D, Joon Won T, Lee YJ, Yoo JS, Eun Hyung K, Won Yoon J, Park SY and Woo Hwang K: Peroxiredoxin-1, a possible target in modulating inflammatory cytokine production in macrophage like cell line RAW264.7. Microbiol Immunol 56: 411-419, 2012.

77. Mennecier G, Torres LN, Cogliati B, Sanches DS, Mori CM, Latorre AO, Chaible LM, Mackowiak II, Nagamine MK Da Silva TC, et al: Chronic exposure of lung alveolar epithelial type II cells to tobacco-specific carcinogen NNK results in malignant transformation: A new in vitro lung carcinogenesis model. Mol Carcinog 53: 392-402, 2014.

78. Yilmaz M and Christofori G: EMT, the cytoskeleton, and cancer cell invasion. Cancer Metastasis Rev 28: 15-33, 2009.

79. Vu T, Jin L and Datta PK: Effect of cigarette smoking on epithelial to mesenchymal transition (EMT) in lung cancer. J Clin Med 5: 44, 2016.

80. Mehdi MZ, Pandey NR, Pandey SK and Srivastava AK: $\mathrm{H} 2 \mathrm{O} 2$-induced phosphorylation of ERK1/2 and PKB requires tyrosine kinase activity of insulin receptor and c-Src. Antioxid Redox Signal 7: 1014-1020, 2005.

81. Shen J, Xu L, Owonikoko TK, Sun SY, Khuri FR, Curran WJ and Deng $X$ : NNK promotes migration and invasion of lung cancer cells through activation of $\mathrm{c}-\mathrm{Src} / \mathrm{PKC} / \mathrm{FAK}$ loop. Cancer Lett 318: 106-113, 2012

82. Zhang H, Liu H, Borok Z, Davies KJ, Ursini F and Forman HJ: Cigarette smoke extract stimulates epithelial-mesenchymal transition through Src activation. Free Radic Biol Med 52: 1437-1442, 2012.

83. Shintani Y, Okimura A, Sato K, Nakagiri T, Kadota Y, Inoue M, Sawabata N, Minami M, Ikeda N, Kawahara K, et al: Epithelial to mesenchymal transition is a determinant of sensitivity to chemoradiotherapy in non-small cell lung cancer. Ann Thorac Surg 92: 1794-1804, 2011.

84. Tseng YC, Tsai YH, Tseng MJ, Hsu KW, Yang MC, Huang KH, $\mathrm{Li}$ AF, Chi CW, Hsieh RH, Ku HH and Yeh TS: Notch2-induced COX-2 expression enhancing gastric cancer progression. Mol Carcinog 51: 939-951, 2012.
85. Ocaña OH, Córcoles R, Fabra A, Moreno-Bueno G, Acloque H, Vega S, Barrallo-Gimeno A, Cano A and Nieto MA: Metastatic colonization requires the repression of the epithelial-mesenchymal transition inducer Prrx1. Cancer Cell 22: 709-724, 2012.

86. Reichert M, Takano S, von Burstin J, Kim SB, Lee JS, Ihida-Stansbury K, Hahn C, Heeg S, Schneider G, Rhim AD, et al: The Prrx1 homeodomain transcription factor plays a central role in pancreatic regeneration and carcinogenesis. Genes Dev 27: 288-300, 2013

87. Lee JM, Dedhar S, Kalluri R and Thompson EW: The epithelial-mesenchymal transition: New insights in signaling, development, and disease. J Cell Biol 172: 973-981, 2006.

88. Ha B, Kim EK, Kim JH, Lee HN, Lee KO, Lee SY and Jang HH: Human peroxiredoxin 1 modulates TGF- $\beta 1$-induced epithelial-mesenchymal transition through its peroxidase activity. Biochem Biophys Res Commun 421: 33-37, 2012.

89. Xu J, Lamouille S and Derynck R: TGF-beta-induced epithelial to mesenchymal transition. Cell Res 19: 156-172, 2009.

90. Yang Y, Pan X, Lei W, Wang J and Song J: Transforming growth factor-betal induces epithelial-to-mesenchymal transition and apoptosis via a cell cycle-dependent mechanism. Oncogene 25: 7235-7244, 2006

91. Derynck R and Akhurst RJ: Differentiation plasticity regulated by TGF-beta family proteins in development and disease. Nat Cell Biol 9: 1000-1004, 2007

92. Gotzmann J, Huber H, Thallinger C, Wolschek M, Jansen B, Schulte-Hermann R, Beug H and Mikulits W: Hepatocytes convert to a fibroblastoid phenotype through the cooperation of TGF-betal and Ha-Ras: Steps towards invasiveness. J Cell Sci 115: 1189-1202, 2002

93. Ushio-Fukai M and Nakamura Y: Reactive oxygen species and angiogenesis: NADPH oxidase as target for cancer therapy. Cancer Lett 266: 37-52, 2008.

94. Jiang F, Qiu Q, Khanna A, Todd NW, Deepak J, Xing L, Wang H, Liu Z, Su Y, Stass SA and Katz RL: Aldehyde dehydrogenase 1 is a tumor stem cell-associated marker in lung cancer. Mol Cancer Res 7: 330-338, 2009.

95. Huang RY, Li MY, Hsin MK, Underwood MJ, Ma LT, Mok TS, Warner TD and Chen GG: 4-Methylnitrosamino1-3-pyridyl-1-butanone (NNK) promotes lung cancer cell survival by stimulating thromboxane A 2 and its receptor. Oncogene 30: 106-116, 2011.

96. Hung YH and Hung WC: 4-(Methylnitrosamino)-1(3-pyridyl)-1-butanone (NNK) enhances invasiveness of lung cancer cells by up-regulating contactin-1 via the alpha7 nicotinic acetylcholine receptor/ERK signaling pathway. Chem Biol Interact 179: 154-159, 2009.

97. Yan J, Wong N, Hung C, Chen WX and Tang D: Contactin-1 reduces E-cadherin expression via activating AKT in lung cancer. PLoS One 8: e65463, 2013.

98. Jin Z, Xin M and Deng X: Survival function of protein kinase $\mathrm{C}\{$ iota $\}$ as a novel nitrosamine 4-(methylnitrosamino)-1-(3pyridyl-1-butanone-activated bad kinase. J Biol Chem 280: 16045-16052, 2005.

99. Wang KC, Liu YC, El-Shazly M, Shih SP, Du YC, Hsu YM, Lin HY, Chen YC, Wu YC, Yang SC and Lu MC: The antioxidant from ethanolic extract of Rosa cymosa fruits activates phosphatase and tensin homolog in vitro and in vivo: A new insight on its antileukemic effect. Int J Mol Sci 20: 1935, 2019.

100. Neumann CA and Fang Q: Are peroxiredoxins tumor suppressors? Curr Opin Pharmacol 7: 375-380, 2007.

101. Nauseef WM: Biological roles for the NOX family NADPH oxidases. J Biol Chem 283: 16961-16965, 2008.

102. Ge GZ, Xu TR and Chen C: Tobacco carcinogen NNK-induced lung cancer animal models and associated carcinogenic mechanisms. Acta Biochim Biophys Sin (Shanghai) 47: 477-487, 2015.

103. Hong WG, Kim JY, Cho JH, Hwang SG, Song JY, Lee E, Chang TS, Um HD and Park JK: AMRI-59 functions as a radiosensitizer via peroxiredoxin I-targeted ROS accumulation and apoptotic cell death induction. Oncotarget 8: 114050-114064, 2017.

This work is licensed under a Creative Commons Attribution-NonCommercial-NoDerivatives 4.0 International (CC BY-NC-ND 4.0) License. 